\title{
Applying SAR-IRSL methodology for dating fine-grained sediments from Lake El'gygytgyn, north-eastern Siberia
}

\author{
Olaf Juschus $^{\mathrm{a}, *}$, Frank Preusser ${ }^{\mathrm{b}}$, Martin Melles ${ }^{\mathrm{a}}$, Ulrich Radtke ${ }^{\mathrm{c}}$ \\ ${ }^{a}$ Institute for Geophysics and Geology, University of Leipzig, Talstrasse 35, D 04103 Leipzig, Germany \\ b Institute of Geological Sciences, Universität Bern, Baltzerstrasse 1-3, CH 3012 Bern, Switzerland \\ ${ }^{\mathrm{c}}$ Geographisches Institut, Universität zu Köln, Albertus-Magnus-Platz, D 50923 Köln, Germany
}

Received 12 October 2005; accepted 1 May 2006

Available online 12 June 2006

\begin{abstract}
Lake El'gygytgyn is situated in a 3.6 Ma old impact crater in north-eastern Siberia and probably represents one of the most complete archives of Arctic climate change. Investigated here is the potential of infra-red stimulated luminescence (IRSL) using the single-aliquot regenerative-dose (SAR) approach for dating sediments from this lake. Independent age control is available from a published age model of a parallel core that is based on tuning sediment proxies with regional insolation and the results of previous multiple aliquot IRSL dating. Although the site is located within volcanic bedrock, anomalous fading seems to have little effect on the calculated ages. The modelled water content for the entire time of burial is seen as the most prominent uncertainty at this particular site. Despite these potential error sources, SAR-IRSL ages are in acceptable agreement with the given timeframe and clearly point to the possibility to establish independent chronologies at this site up to at least 400,000 years.
\end{abstract}

(C) 2006 Published by Elsevier Ltd.

Keywords: SAR-IRSL methodology; Lake El'gygytgyn; Lake sediments

\section{Introduction}

Luminescence dating is recently used to date samples from a variety of depositional environments, mainly of aeolian and fluvial origin. Surprisingly, relatively few studies have reported on attempts to date lacustrine sediments, although such deposits represent very important archives of past environmental change on the continents and are thus of crucial relevance for reconstructing the Quaternary climate history. Early work by Kronborg (1983) and Berger (1990) concentrated on studying the amount of resetting of thermoluminescence (TL) in modern sediments and on dating deposits of known age, highlighting both the potential and limitations of TL. The introduction of optically stimulated luminescence (OSL) opened new dimensions in the dating of water-lain sediment due to the higher bleachability of the optical signal (Huntley et al., 1985). Ditlefsen (1992) experimen-

\footnotetext{
${ }^{*}$ Corresponding author. Tel.: + 49341 9732907; fax: + 493419732809.

E-mail address: juschus@rz.uni-leipzig.de (O. Juschus).
}

tally investigated the bleaching of sediment suspensions demonstrating that the optical signal is almost completely bleached in dilute suspensions within a few hours. In dense suspensions, in contrast, only little bleaching of luminescence was observed. Krause et al. (1997) used infra-red stimulated luminescence (IRSL) to date lake deposits from Antarctica and compared four different emission bands of IRSL $(280,330,410,560 \mathrm{~nm})$. The inconsistent results of equivalent dose $\left(D_{\mathrm{e}}\right)$ measurements were attributed to different bleaching characteristics of the different emission bands. However, Preusser (1999) found no differences in bleaching characteristics of different IRSL emissions for samples from Switzerland.

Late Glacial to Holocene sediments from Lake Holzmaar, Germany, gave IRSL ages consistent with varve chronology for samples with low concentrations of biogenic material. Inaccurate ages obtained for organic rich samples are explained by problems with correct dose rate determination (Lang and Zolitschka, 2001). Thomas et al. (2003) applied different approaches to date lacustrine deposits from Greece revealing an underestimation of 
polymineral fine grain IRSL and post-IR OSL UV emissions compared to quartz OSL ages and radiocarbon chronology. It was demonstrated that the underestimation of IRSL ages was due to anomalous fading that was observed in storage tests. However, the presence of fading is probably explained by using IRSL UV emissions or by a specific geological setting at that particular site since other studies on dating lacustrine sediments using blue emissions gave correct age estimates (Doran et al., 1999; Wolfe et al., 2000; Berger and Doran, 2001; Berger et al., 2004). On the other hand, Vandergoes et al. (2005) dated a 150,000 years lake record from Okarito Pakihi, New Zealand, and got IRSL and post-IR OSL in agreement with the results of radiocarbon dating, tephra chronology and the chronological time frame deduced from comparison with pollen records from ocean sediment.

The present study presents the results of dating a lacustrine sediment succession recovered from Lake El'gygytgyn, north-eastern Siberia, using the IRSL singlealiquot regenerative-dose (SAR) technique applied to polymineral fine-grains. This site is ideal for testing this particular dating approach because an independent age model exists based on correlation with a parallel core that was dated by tuning the magnetic and geochemical properties of the sediments with the regional insolation (Nowaczyk et al., in press). Furthermore, a previous study has demonstrated the reliability of optical dating back to as far as 150,000 years using multiple aliquot additive dose (MAAD) approaches (Forman et al., in press). The advantage of SAR methodology is a higher precision and the potential to extend the age range to be dated. This is due to the fact that regenerative dose techniques allow to more closely approach the saturation dose than it is possible by MAAD methodology. Furthermore, no extrapolation of dose response curves is necessary, which is a potential source of inaccuracy in MAAD dating, especially at higher doses. However, it may be possible that other problems arise when using the SAR technique, such as the influence of short-term fading, due to the fact that samples are not stored after irradiation.

\section{Site information and age model}

\subsection{Site information}

Lake El'gygytgyn is located in a meteorite impact crater, roughly $18 \mathrm{~km}$ in diameter, that was formed $3.58 \pm 0.04 \mathrm{Ma}$ ago (Layer, 2000) in Late Cretaceous volcanic rocks on the Chukotka Peninsula, north-eastern Siberia (Fig 1). The lake itself has a diameter of about $12 \mathrm{~km}$ and a water depth of $170 \mathrm{~m}$. While the crater rim has present elevations between 600 and $930 \mathrm{~m}$, the surface of the lake lies at $492 \mathrm{~m}$ above sea level. About 50 small inlet streams drain into the lake. The only outlet (Enmyvaam River, Fig. 1) exits to the south. Due to its position about $100 \mathrm{~km}$ to the north of the Arctic Circle the lake surface remains ice-covered for about 9 months of the year. The open water season usually starts

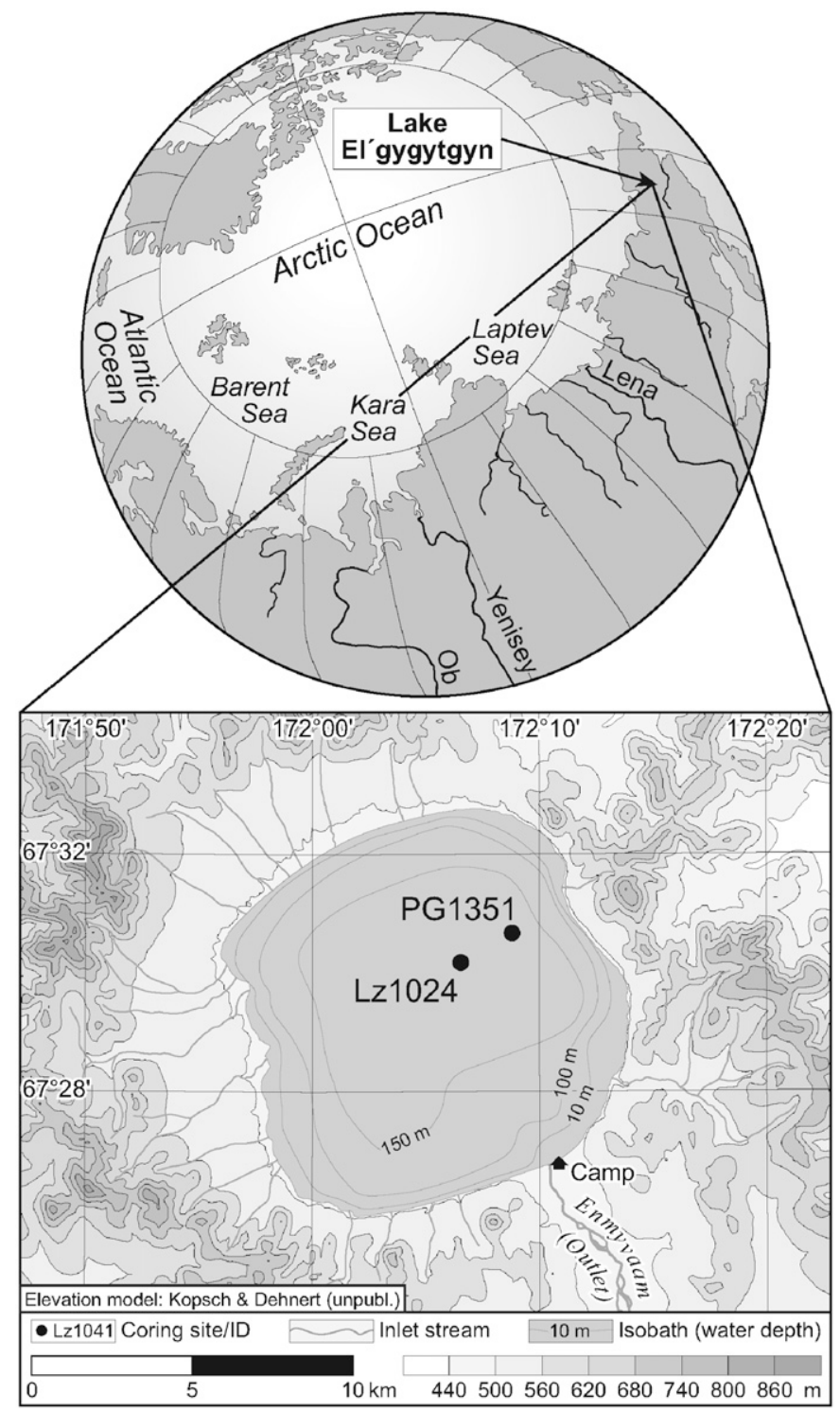

Fig. 1. Location of Lake El'gygytgyn in north-eastern Siberia (upper part) and position of cores PG1351 and Lz1024 in the deepest part of the lake (lower part).

during the mid of July. A complete lake ice cover does not become formed again until Late October (Nolan et al., 2003).

The lake area has never been glaciated during the Quaternary (Glushkova and Smirnov, 2005) and probably never gone dry (Niessen et al., in press). Thus, Lake El'gygytgyn probably contains the longest continuous terrestrial record of Arctic climate change. This suggestion is supported for the past $250 \mathrm{ka}$ by the chronology and composition of a $13 \mathrm{~m}$ long sediment core (PG1351, Fig. 1) recovered in 1998 (e.g. Nowaczyk et al., in press; Melles et al., in press). Core Lz1024, recovered in 2003 and studied here, is about $3 \mathrm{~m}$ longer than PG1351.

The sediments of central Lake El'gygytgyn are mostly silts and clays containing some fine sand and occasional gravel and coarser material (Asikainen et al., in press). 
Usually the sediments settled during warm periods (e.g. equivalents of Marine Isotope Stages (MIS) 1 and 3) are coarser than the material of cold intervals (e.g. MIS 2 and 4). The main sediment transport process carrying material into the lake basin is still a matter of controversy. While Forman et al. (in press) mentioned both fluvial and aeolian supply into the lake Juschus et al. (2005) preferred fluvial input seconded by ice flow rafting. However, it is unchallenged that aeolian material is blown on the longlasting lake ice cover allowing the supply of comparatively coarse-grained material to the centre of the lake.

\subsection{Age model}

The age model of core PG1351 (Fig. 2), recovered in 1998, was deduced from tuning regional insolation with magnetic susceptibility, biogenic silica, total organic carbon and $\mathrm{TiO}_{2}$ values in the sediments (Nowaczyk et al., in press; Melles et al., in press). It is confirmed by pollen analyses, AMS radiocarbon and MAAD polymineral fine-grain IRSL dating (Nowaczyk et al., 2002; Nowaczyk et al., in press; Forman et al., in press).

The preliminary age model for the newly drilled core Lz1024 (Fig. 2) was developed using both isochronous sediment layers and susceptibility variations to correlate core Lz1024 with the well-dated core PG1351. Juschus et al. (2004) have demonstrated that fine-grained turbidites

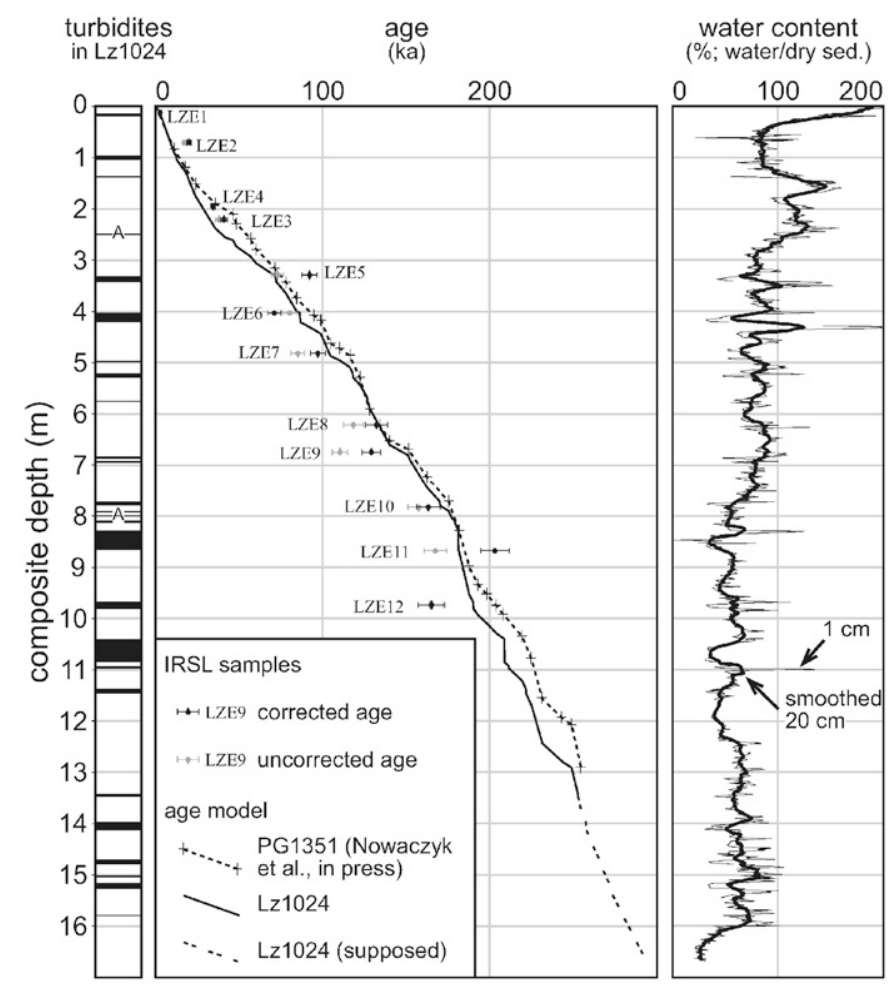

Fig. 2. Age model of core Lz1024 as based on correlation with core PG1351 (Nowaczyk et al., in press), and water content of core Lz1024 together with the uncorrected (Table 1, Wa and Age a) and corrected IRSL ages ( $W c$ and Age c). The positions of turbidites (black bars) and ash layers (A) is given on the left side. being common features in the cores, were deposited across the whole lake basin, thus, making them extremely useful chronostratigraphic marker horizons. In addition, two ash layers were recognised as isochrons within both cores. PG1351-ages of these layers were transmitted to core Lz1024. The age interpolation of the intervals in between is based on the assumption of constant sedimentation rates. Finally the age model obtained was verified using the susceptibility data, which show an excellent correlation between the two cores. This indicates firstly, that both cores reflect a continuous deposition and, secondly, that the sediment successions are not influenced by local events but reflect the regional climatic and environmental history. Based on the age model, the $16.7 \mathrm{~m}$ long core Lz1024 penetrates down to about 300,000 years BP and currently represents the longest continuous record of this type in the entire Arctic.

\section{Methods}

\subsection{Sampling, sample preparation and measurement conditions}

Both cores, PG1351 and Lz1024, were recovered with UWITEC (Austria) coring equipment. A gravity corer was used for proper sampling of the water-sediment transition. Deeper sediments were collected with a percussion piston corer. The piston corer enables sampling of up to 3-m-long sections from defined sediment depths. Thus, much longer composite core sequences can be obtained by coring of several overlapping sections. PG1351 was recovered in April 1998 trough holes in the lake ice cover, Lz1024 in the same manner in May 2003. The cores were stored in opaque plastic liners with a diameter of $6 \mathrm{~cm}$. They were kept cool but above $0{ }^{\circ} \mathrm{C}$ and remained closed until arriving at the laboratories. For proper sampling for IRSL dating about $10 \mathrm{~cm}$ were cut from the ends of the individual liners of core Lz1024. These liner pieces were opened under subdued red-light laboratory conditions and the inner part was used for further investigations only. Samples LZE5, LZE6, and LZE10 were partly taken from turbidites, while sample LZE12 is completely composed of a turbidite (Fig. 2). Although turbidites have previously been thought to be unsuitable for OSL dating due to zeroing problems in turbid undercurrents, we decided to attempt the dating of such layers.

The material used for equivalent dose $\left(D_{\mathrm{e}}\right)$ determination was chemically pre-treated using $10 \%$ hydrogenchloride, $30 \%$ hydrogeneperoxide and sodium-oxalate. The fraction 4-11 $\mu \mathrm{m}$ was enriched using Stokes' law. The dried material was dissolved in acetone and deposited as thin layers on aluminium discs. $D_{\mathrm{e}}$ was determined using the modified SAR protocol for feldspar as described by Preusser (2003). Natural and regenerative dose points were pre-heated at $290^{\circ} \mathrm{C}$ for $10 \mathrm{~s}$ and a cut heat of $200^{\circ} \mathrm{C}$ was applied prior to all test dose measurements. The applicability of the approach was verified by dose recovery tests (average 


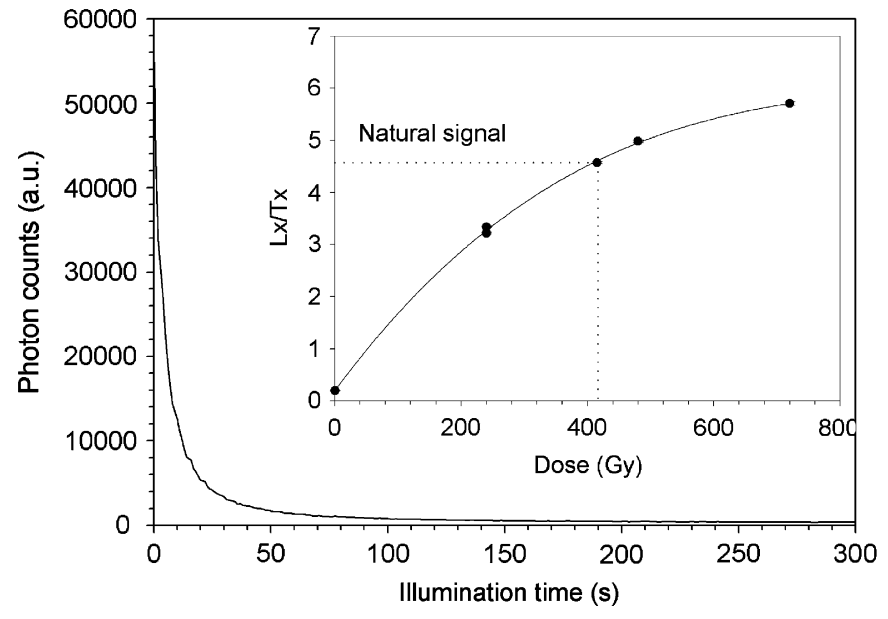

Fig. 3. IRSL shine down curve of an aliquot of sample LZE12. Inlet: Dose response curve of an aliquot of the lowermost investigated sample (LZE12) so far. No indication of saturation for the given highest regenerative dose is being observed.

recovery ratio $=0.98)$. IRSL was recorded during $300 \mathrm{~s}$ stimulation by IR diodes (Fig. 3). The final $60 \mathrm{~s}$ were subtracted from the rest of the signal as late-light (Aitken and Xie, 1992; Lang and Wagner, 1997). The lowest regenerative dose was measured twice, at the beginning and the end of each SAR cycle (Fig. 3), to investigate the degree of sensitivity change correction (recycling ratio). The average recycling ratio of all measured aliquots is 1.06.

\subsection{Dose rate determination}

Determination of dose rate relevant elements $(\mathrm{K}, \mathrm{Th}, \mathrm{U})$ was done by ICP-MS (Preusser and Kasper, 2001). Unfortunately, the scarcity of material did not allow to cross check the results of ICP-MS by high-resolution $\gamma$-spectrometry leaving some uncertainty if the investigated sediment are in radioactive equilibrium. However, reports from previous studies have demonstrated that lacustrine sediment is apparently not affected by disequilibrium as long as contents of organic matter and primary carbonates are low, both originating from increased bioproductivity (Lang and Zolitschka, 2001; Thomas et al., 2003; Preusser et al., 2005). Since Lake El'gygytgyn shows relatively low contents of organic material it is unlikely that correct dose rate determination is affected by this problem. The contribution by cosmic rays to the total dose rate is almost negligible since the sediment is deposited $170 \mathrm{~m}$ below the lake surface.

Sediment water content is an important factor that significantly affects the dose rate of lake sediments after deposition. Thus, modelling the mean water content since deposition (modelled water content) is essential for correcting IRSL ages of lake sediments. However, it is difficult to reconstruct the dehydration of lake sediments properly because the reconstruction is based on various assumptions. As a consequence, the calculation of mean water content as discussed below has an approximate character. For the measurement of present water content of core Lz1024 all sub-samples (each $\mathrm{cm}$ ) were freeze-dried and their water contents (in \% of dry bulk sediment) were calculated from the mass differences between the wet and dry samples.

\subsection{Fading tests}

Fading of the luminescence signal is a potential error source when using feldspars as natural dosimeters, especially since Lake El'gygytgyn is located within volcanic bedrock. However, Forman et al. (in press) could in their storage tests not observe a significant loss of the artificially induced IRSL signal, implying that the samples are not affected by (measurable) fading. We performed additional storage tests to investigate if any loss of artificially induced IRSL is present. This was done by bleaching one set of five aliquots of each sample overnight (Osram Ultravita Lux), irradiating and preheating these aliquots, and measuring the IRSL response to $0.1 \mathrm{~s}$ exposure to IR diodes (short shine). For a second batch of three aliquots, natural IRSL was preheated and measured by short shines. Afterwards, samples were stored at room temperature for 4 months and subsequently IRSL response were measured during short shines. For both measurements an average ratio of natural/ artificial IRSL signal was calculated. The fading ratio is calculated by dividing the value of the second by the value of the first measurement. In the absence of fading this ratio will be 1.00 and in the presence of fading it will be smaller.

\section{Results and discussion}

IRSL ages calculated for core Lz1024 range between $2.4 \pm 1.4 \mathrm{ka}$ (LZE1) for the top of the sequence and $203 \pm 17 \mathrm{ka}$ (LZE12) at the bottom of the core (Table 1 and Fig. 2). Half of the SAR-IRSL ages presented here agree well with the proposed age model of core Lz1024. Exceptions are samples LZE2, LZE5, and LZE11, which gave ages higher than expected, and LZE6, LZE9, and LZE12 for which we calculated lower ages than expected. Possible explanations are, beside random error, incomplete bleaching of IRSL prior to deposition (see Section 4.1), fading of IRSL (see Section 4.2), and incorrect determination of dose rate, in particular due to inappropriate estimation of modelled water content (see Section 4.3).

\subsection{Incomplete bleaching}

Incomplete bleaching of IRSL is a potential source when dating most kinds of water-lain deposits. However, previous reports imply that most lacustrine sediments investigated so far are not affected by partial bleaching (e.g. Lang and Zolitschka, 2001; Wolfe et al., 2000; Vandergoes et al., 2005). Investigating measurement time dependant changes in $D_{\mathrm{e}}$ estimates (shine plateau test) does not reveal any indication for partial bleaching. The plot is 


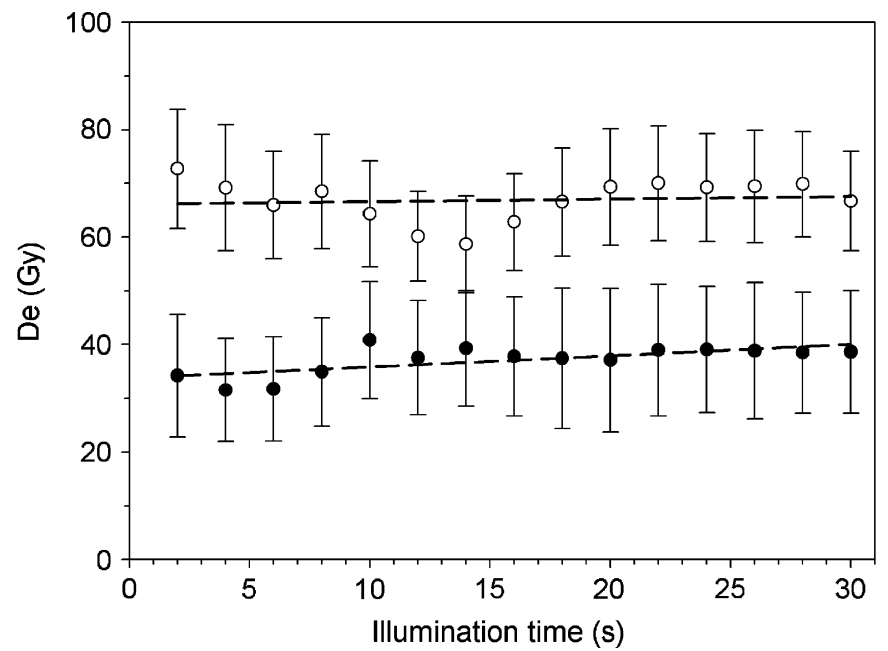

Fig. 4. Plot of $D_{\mathrm{e}}$ versus stimulation time for an aliquot of sample LZE2 (closed sysmbols) and LZE4 (open symbols). Although sample LZE2 significantly overestimates the expected age according the age model, the flat plot give no indication for partial bleaching of IRSL prior to deposition.

flat and does not show any increase of $D_{\mathrm{e}}$ with measurement time, as would be expected for incompletely bleached samples (Fig. 4). However, this fact does not explicitly confirm complete bleaching of samples due to possible interferences with other phenomenon (cf. Aitken, 1998).

Apparent age overestimation is presumably also not to be explained by the turbidite layers found in the sequence. Sample LZE2, showing the highest relative overestimation, is well above such a layer and the IRSL age of sample LZE12 from a turbidite, for example, is too young rather than too old. However, it is rather unlikely that sediment is sufficiently long enough exposed to sunlight during a turbidite event, considering both the rapid nature of the event and absorption of daylight by water column. This apparent discrepancy between the dating results and expectations based on geological background of the sedimentation process is likely to be explained by the fact that turbidites are mainly composed of material that was eroded from sediments freshly settled in the proximity to the lake shore (Juschus et al., 2004). These sediments were probably only a few thousand years older than the turbidite event. Especially for the lower part of the core the lack between primary deposition and turbidite event will thus be negligible.

\subsection{Fading tests}

We found fading ratios between $0.99 \pm 0.12$ (LZE8) and $0.84 \pm 0.14$ (LZE6), being similar to the values reported by Forman et al. (in press) from core PG1351. Although, all mean values of the fading ratio are smaller than 1.00, the uncertainty associated with most of these measurements does not allow concluding that part of the investigated IRSL is instable. We thus followed Forman et al. (in press) 
and applied no fading correction as suggested by e.g. Huntley and Lamothe (2001). However, some influence of fading on age calculation cannot explicitly be excluded, especially for samples LZE6 and LZE12. Both samples actually show the strongest implication of possible fading with fading ratios of $0.84 \pm 0.14$ and $0.89 \pm 0.03$. Hence, some effect of fading on age determination has to be considered, especially for the seen two samples. LZE6 is mainly composed of a strong $\mathrm{Fe} / \mathrm{Mn}$-layer while LZE12 was completely taken from a turbidite which moved fluvial and, hence, volcanic material from the lake proximity to the centre. It is possible that both the new composed $\mathrm{Fe} /$ Mn minerals within LZE6 and the volcanic material within LZE12 are responsible for the apparently higher the fading ratios.

\subsection{Influence of water content on age calculation}

The water content of core Lz1024 is characterised by a decreasing trend with depth due to natural consolidation of sediment (Fig. 2). In the uppermost part of the core the sediment is highly over-saturated by water (water contents around 190\%). Within a few decimetres, respectively the younger Holocene, the content of water decrease dramatically (down to ca. 90\%) and reaches values of about $50-60 \%$ in the lowermost part of the core. Furthermore, frequent and partly abrupt changes in water content occur.

During the last glacial sediment (1.2-1.7 $\mathrm{m}$ depth, Fig. 2) the water content is significantly higher than during the Lower Holocene, probably due to the high clay content of these sediments (Asikainen et al., in press). This effect is reversing towards the older cold stages with slightly lower water contents than found for warm stage sediments (cf. Fig. 2, changes in water content at 9.6 and $12.4 \mathrm{~m}$ depth). This is probably due to a more effective compaction of the more clayey deposits and, hence, a reduced pore volume (cf. Füchtbauer, 1988).

This pattern is further complicated by the frequent occurrence of sedimentary layers enriched in iron and manganese. These layers were formed during warm stages at the boundary of oxic to anoxic sediments and later became reduced when this boundary migrated upwards. Similar layers have been described from Lake Baikal (Granina et al., 2004). The formation of $\mathrm{Fe} / \mathrm{Mn}$-layers interfered with sediment dehydration by an unknown factor and it may also be possible that these layers are not in radioactive equilibrium. For example, distinct peaks in water content at 2.3,3.4, and $4.25 \mathrm{~m}$ depth (Fig. 2) occur in such layers, being partly sampled by LZE3, LZE4, LZE6, LZE8 and LZE9. Turbidite layers are characterised by significantly lower water contents (Fig. 2, depths 1.4, $3.3,4.1 \mathrm{~m}$, etc.). The two uppermost turbidites are an exception probably due to their young age and slow dehydration.

In order to approach the changes in water content based on sedimentary changes four sediment classes are assigned for the determination of modelled water content since deposition (Table 1):

- sediments deposited under warm climatic conditions (labelled "warm" in Table 1);

- sediments deposited under cold climatic conditions (labelled "cold");

- $\mathrm{Fe} / \mathrm{Mn}$-enriched sedimentary layers within warm period sediments (labelled "Fe/Mn");

- turbidites (labelled "turbidite").

We approached the impact of fluctuations in water content by employing three different values for the calculation of the dose rates and IRSL ages (Table 1). The first value (a) is based on the average water content measured for the sampled segment of the core. This value is representative for calculating the attenuation of especially $\alpha$ - and $\beta$-irradiation by water at present day. The second value (b) is based on averaging the water content of the whole sediment $30 \mathrm{~cm}$ above and below the middle of the sample, which represents the part of the core that affects the sample by $\gamma$-irradiation. True attenuation of irradiation will be between these two values but we did not further attempt to calculate a mean value due to the fact that water content changed during burial time, mainly due to sediment consolidation. In consequence, a third water content value ( $c$, modelled water content) is estimated based on the four sediment classes. The modelled mean water content for the IRSL samples is determined by calculating the average of all water contents (each $\mathrm{cm}$ ) between the sediment surface and the IRSL-sample. But we only account for selected values from the same sediment class from which the respective IRSL sample was taken. The values from sediments belonging to another sediment class have been ignored.

Uncertainties associated with the correct estimation of mean water content are a likely explanation for IRSL ages inconsistent with the age model. As stated above, the modelled water content is only an attempt to approximate natural conditions. For some samples (e.g. LZE5) the modelled water content apparently overestimates natural conditions and using the much lower present-day value would give an age estimate in good agreement with the age model. However, present-day values are unlikely to be representative for the whole time period since deposition considering substantial consolidation of sediment in the lower part of the sequence. Some kind of correction seems thus to be necessary and it will be the objective of future research to improve models for calculating the modelled water content.

\section{Conclusions}

SAR-IRSL dating of Lake El'gygytgyn gave results in acceptable agreement with the available multi-proxy age model. Despite the fact that the lake is situated within volcanic bedrock, anomalous fading seems to have a 
limited effect on the calculation of ages. This is different to samples collected from the slopes of the impact crater, which show a mixture of strong fading (ca. 30\%) and nonfading (ca. 70\%) feldspars (Visocekas, pers. comm.). A pure input of sediment from the slope would most likely result in higher fading ratio then the ones observed in storage tests reported both here and by Forman et al. (in press). As a consequence, a substantial aeolian input of non-fading material into the lake needs to be considered to explain this apparent discrepancy.

Dose response curves demonstrate that the IRSL signal is far from saturation, implying the potential to substantially extend the range to be dated to at least 400,000 years. This is a promising perspective since it is the aim of a forthcoming drilling programme within the scope of the International Continental Drilling Programm (ICDP) to recover the whole 3,600,000 years lacustrine sediment sequence and thus probably one of the most complete archives of continental palaeoclimatic history. SAR-IRSL dating will probably be an important tool to provide independent age control in the upper part of the sediment sequence.

\section{Acknowledgements}

The expedition to Lake El'gygytgyn in 2003 and the following post-processing was mainly funded by the German Federal Ministry for Education and Research (BMBF; Grant no. 03G0586A, B). Raphael Visocekas (Paris, France) carried out complementary fading experiments on samples from the crater slope, which is highly acknowledged. Sample preparation was carried out by Sung-Won Choi and measurements were made at the Luminescence Laboratories of the University of Cologne. Haino Uwe Kasper (University of Cologne) carried out the ICP-MS measurements. Thanks are also due to Sven Lukas (previously at St. Andrews, UK, now at Bern, Switzerland) for his proof reading and an anonymous reviewer for his/ her comments.

\section{Editorial handling by: R. Roberts}

\section{References}

Aitken, M.J., 1998. An introduction to optical dating. University Press, Oxford, $267 \mathrm{pp}$.

Aitken, M.J., Xie, J., 1992. Optical dating using infrared diodes: young samples. Quaternary Science Reviews 11, 147-152.

Asikainen, C.A., Francus, P., Brigham-Grette, J., in press. Sedimentology, clay mineralogy and grain-size as indicators of $65 \mathrm{ka}$ of climate change from El'gygytgyn Crater Lake, Northeastern Siberia. Journal of Paleolimnology.

Berger, G.W., 1990. Effectiveness of natural zeroing of the thermoluminescence in sediments. Journal of Geophysical Research 95, 12375-12397.

Berger, G.W., Doran, P.T., 2001. Luminescence-dating zeroing tests in Lake Hoare, Taylor Valley, Antarctica. Journal of Paleolimnology 25, 519-529.
Berger, G.W., Melles, M., Banerjee, D., Murray, A.S., Raab, A., 2004. Luminescence chronology of non-glacial sediments in Changeable Lake, Russian High Arctic, and implications for limited Eurasian icesheet extent during the LGM. Journal of Quaternary Science 19, 513-523.

Ditlefsen, C., 1992. Bleaching of K-feldspars in turbid water suspensions: a comparison of photo- and thermoluminescence signals. Quaternary Science Reviews 11, 33-38.

Doran, P.T., Berger, G.W., Lyons, W.B., Wharton, R.A., Davisson, M.L., Southon, J., Dibb, J.E., 1999. Dating Quaternary lacustrine sediments in the McMurdo Dry Valleys, Antarctica. Palaeogeography, Palaeoclimatology, Palaeoecology 147, 223-239.

Forman, S.L., Pierson, J., Gomez, J., Brigham-Grette, J., Nowaczyk, N.R., Melles, M., in press. Luminescence geochronology for sediments from Lake El'gygytgyn, northwest Siberia, Russia: constraining the timing of paleoenvironmental events for the past $200 \mathrm{ka}$. Journal of Paleolimnology.

Füchtbauer, H., 1988. Sedimente und Sedimentgesteine, Sedimentpetrologie Teil II. Schweizerbart, Stuttgart, $1141 \mathrm{pp}$

Glushkova, O.Y., Smirnov, V.N., 2005. General geology and geography. In: Melles, M., Minyuk, P.S., Brigham-Grette, J., Juschus, O., (Eds.), The Expedition El'gygytgyn Lake 2003 (Siberian Arctic). Reports on Polar and Marine Research 509, pp. 14-18

Granina, L., Müller, B., Wehrli, B., 2004. Origin and dynamics of Fe and Mn sedimentary layers in Lake Baikal. Chemical Geology 205, 55-72.

Huntley, D.J., Godfrey-Smith, D.I., Thewalt, M.L.W., 1985. Optical dating of sediments. Nature 313, 105-107.

Huntely, D.J., Lamothe, M., 2001. Ubiquity of anomalous fading in Kfeldspar and the measurement and correction for it in optical dating. Canadian Journal of Earth Science 38, 1093-1106.

Juschus, O., Melles, M., Brigham-Grette, J., Dehnert, A., Gebhardt, C., Niessen, F., Minyuk, P.S., Wennrich, V., 2004. The significance of Late Quaternary mass movement events for the paleoenvironmental interpretation of sediment records from Lake El'gygytgyn, NE Siberia. Eos Trans. AGU 85 (47), Fall Meeting Supplement PP21B-1387.

Juschus, O., Fedorov, G., Wennrich, V., Quart, S., 2005. Aeolian supply. In: Melles, M., Minyuk, P.S., Brigham-Grette, J., Juschus, O. (Eds.), The Expedition El'gygytgyn Lake 2003 (Siberian Arctic). Reports on Polar and Marine Research 509, pp. 52-54.

Krause, W.E., Krbetschek, M.R., Stolz, W., 1997. Dating Quaternary lake sediments from the Schirmacher Oasis (East Antarctica) by Infra-red stimulated luminescence (IRSL) detected at the wavelength of $560 \mathrm{~nm}$. Quaternary Science Reviews 16, 387-392.

Kronborg, C., 1983. Preliminary results of age determination by TL of interglacial and interstadial sediment. PACT Journal 9, 595-605.

Lang, A., Wagner, G.A., 1997. Infrared stimulated luminescence dating of Holocene colluvial sediments using the $410 \mathrm{~nm}$ emission. Quaternary Science Reviews 16, 393-396.

Lang, A., Zolitschka, B., 2001. Optical dating of annually laminated lake sediments: a test case from Holzmaar/Germany. Quaternary Science Reviews 20, 737-742.

Layer, P.W., 2000. ${ }^{40} \mathrm{Ar} /{ }^{39} \mathrm{Ar}$ age of the El'gygytgyn impact event, Chukotka, Russia. Meteoritics \& Planetary Science 35, 591-599.

Melles, M., Brigham-Grette, J., Glushkova, O.Y., Minyuk, P.S., Nowaczyk, N.R., Hubberten, H.W., in press. Sedimentary geochemistry of a pilot core from Lake El'gygytgyn - a sensitive record of climate variability in the East Siberian Arctic during the past three climate cycles. Journal of Paleolimnology.

Niessen, F., Gebhardt, A.C., Kopsch, C., Wagner, B., in press. Seismic investigation of the El'gygytgyn impact crater lake (Central Chukotka, NE Siberia): preliminary results. Journal of Paleolimnology.

Nolan, M., Liston, G., Prokein, P., Brigham-Grette, J., Sharpton, V.L., Huntzinger, R., 2003. Analysis of lake ice dynamics and morphology on Lake El'gygytgyn, NE Siberia, using synthetic aperture radar (SAR) and Landsat. Journal of Geophysical Research 108 (D2), 8162.

Nowaczyk, N.R., Minyuk, P., Melles, M., Brigham-Grette, J., Glushkova, O., Nolan, M., Lozhkin, A.V., Stetsenko, T.V., Andersen, P.M., Forman, S.L., 2002. Magnetostratigraphic results from impact crater 
Lake El'gygytgyn, northeastern Siberia: a 300 kyr long high-resolution terrestrial palaeoclimatic record from the Arctic. Geophysical Journal International 150, 109-126.

Nowaczyk, N.R., Melles, M., Minyuk, P.S., in press. A revised age model for core PG1351 from Lake El'gygytgyn, Chukotka, based on magnetic susceptibility variations tuned to northern hemisphere insolation variations. Journal of Paleolimnology.

Preusser, F., 1999. Bleaching characteristics of some optically stimulated luminescence signals. Ancient TL 17, 11-14.

Preusser, F., 2003. IRSL dating of K-rich feldspars using the SAR protocol: comparison with independent age control. Ancient TL 21, $17-23$.

Preusser, F., Kasper, H.U., 2001. Comparison of dose rate determination using high-resolution gamma spectrometry and inductively coupled plasma-mass spectrometry. Ancient TL 19, 17-21.
Preusser, F., Drescher-Schneider, R., Fiebig, M., Schlüchter, Ch., 2005. Re-interpretation of the Meikirch pollen record, Swiss Alpine Foreland, and implications for Middle Pleistocene chronostratigraphy. Journal of Quaternary Science 20, 607-620.

Thomas, P.J., Murray, A.S., Sandgren, P., 2003. Age limit and age underestimation using different OSL signal from lacustrine quartz and polymineral fine grains. Quaternary Science Reviews 22, 1139-1143.

Vandergoes, M., Newnham, R., Preusser, F., Hendy, C., Lowell, T., Fitzsimons, S., Hogg, A., Kasper, H.U., Schlüchter, Ch., 2005. Southern Ocean terrestrial record showing local modification of glacial-interglacial climate signals. Nature 436, 242-245.

Wolfe, A.P., Fréchette, B., Richard, P.J.H., Miller, G.H., Forman, S.L., 2000. Paleoecology of $a>90,000$-year lacustrine sequence from Fog Lake, Baffin Island, Arctic Canada. Quaternary Science Reviews 19 , 1677-1699. 